\title{
Effect of Glucose Concentrations on the Growth and Metabolism of Brettanomyces bruxellensis under Aerobic Conditions
}

\author{
Ortiz-Muñiz Benigno ${ }^{1}$, Corro-Herrera Victor ${ }^{2}$, Gomez-Rodriguez Javier²,

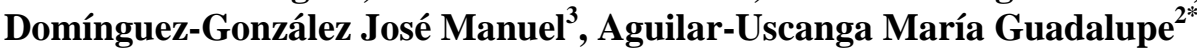 \\ ${ }^{1}$ Instituto Tecnológico Superior de Tierra Blanca, Av. Veracruz s/n. Col. PEMEX, Veracruz, México \\ ${ }^{2}$ Instituto Tecnológico de Veracruz, Unidad de Investigación y Desarrollo en Alimentos (UNIDA), Dpto Ing. Eléctrica y \\ Electrónica, Col. Formando Hogar, Veracruz, México \\ ${ }^{3}$ Universidad de Vigo, Departamento de Ingeniería Química, Facultad de Ciencias, Campus Ourence, \\ Ourense, Spain \\ Email: *aguilar@itver.edu.mx
}

Received April 24, 2013; revised May 24, 2013; accepted June 20, 2013

Copyright (C) 2013 Ortiz-Muñiz Benigno et al. This is an open access article distributed under the Creative Commons Attribution License, which permits unrestricted use, distribution, and reproduction in any medium, provided the original work is properly cited.

\begin{abstract}
Acetic acid can be directly produced from glucose in one-step fermentation by using yeasts of the genus Brettanomyces bruxellensis, hence increasing the industrial application to manufacture products with simplified bioprocesses. Thereby, this work evaluates the influence of initial glucose concentration on the growth and acetic acid production by B. bruxellensis. The results obtained confirmed the presence of Crabtree effect on B. bruxellensis under low glucose concentrations. The maximum acetic acid concentration reached was $15.4 \mathrm{~g} \cdot \mathrm{L}^{-1}$ starting with $100 \mathrm{~g} \cdot \mathrm{L}^{-1}$ leading to a product yield of $0.154 \mathrm{~g} \cdot \mathrm{g}^{-1}$ and a specific acetic acid production rate of $0.05 \mathrm{~g} \cdot \mathrm{g}^{-1} \cdot \mathrm{h}^{-1}$. The results also indicate that after reaching the acetic acid critic threshold of $4 \mathrm{~g} \cdot \mathrm{L}^{-1}$ the metabolism can induce the growth second phase even residual glucose was present on the culture media at high starting glucose concentrations. Additionally, it was observed a lineal relationship between cell viability and acetic acid production.
\end{abstract}

Keywords: Glucose; Brettanomyces bruxellensis; Acetic Acid; Inhibition; Crabtree Effect

\section{Introduction}

Acetic acid $\left(\mathrm{CH}_{3} \mathrm{COOH}\right)$ is an organic acid widely employed in pharmaceutical, chemical and food industries. This acid can be produced industrially both synthetically and by bacterial fermentation. The first method comprises the chemical reaction from petroleum; therefore, the resulting product cannot be employed in food applications since many laws concerning purity of foods stipulate that vinegar used in foods must possess a biological origin. Alternatively, acetic acid can be industrially produced by biochemical routes, although this process accounts for only $10 \%$ of world production, in part due to the sophistication of the technology, which involves an alcoholic fermentation by yeasts such as Saccharomyces cerevisiae, followed by an ethanol aerobic oxidation by Acetobacter aceti, resulting into a process with a high-energy consumption [1]. Alternatively, the

\footnotetext{
"Corresponding author.
}

use of Brettanomyces yeasts could simplify the process for a larger-scale bioproduction, considering that this microorganism not only produces acetic acid from sugars in one step due to the presence of Custer effect, but also has low nutritional requirements as compared with other acetic acid bacteria such as Acetobacter species [2]. The Custer effect (also called Pasteur negative effect) on Brettanomyces yeasts stimulates the ethanol and acetic acid production under aerobic conditions [3], where the redox imbalance caused by acetic acid production provokes the incapability to produce glycerol by these yeasts [4]. As well as Pasteur effect was related to the presence of oxygen and sugars concentration [5], the Custer effect was associated to the concentration of sugars. In addition, Wijsman [6] postulated that resting cells of a Brettanomyces sp. grown aerobically had different phases of metabolic activity in which glucose was first dissimilated into ethanol, acetic acid, and equivalent amounts of $\mathrm{CO}_{2} ; \mathrm{a}$ second phase where ethanol was converted into acetic acid; 
and finally, the complete oxidation of the acetic acid produced in both phases into $\mathrm{CO}_{2}$ after a long lag phase. Consequently, the metabolic aspects of Brettanomyces spp. must be carefully considered in order to establish the best operational conditions to improve the acetic acid production. Castro et al. [2] evaluated the capability of different yeasts belonging to the genus Brettanomyces such as B. bruxellensis, custersianus, intermedius and clausenni to produce acetic acid under aerobic conditions, finding that B. bruxellensis achieved the highest volumetric productivity and specific production rate. Additionally, starting with $50 \mathrm{~g} \cdot \mathrm{L}^{-1}$ glucose and $\mathrm{pH} 5.5$ not controlled, in an aerobic fermentation performed with a flow rate of $121 \mathrm{mg} \mathrm{O}_{2} \mathrm{~L}^{-1} \cdot \mathrm{h}^{-1}$ and $250 \mathrm{rpm}$, using $B$. bruxellensis these authors were able to overcome the critic threshold of $4 \mathrm{~g} \cdot \mathrm{L}^{-1}$ acetic acid previously reported by [7] yielding $0.14 \mathrm{~g} \cdot \mathrm{g}^{-1}$ acetic acid. However the combine inhibition effect of glucose and acetic acid limited the process. The glucose inhibition phenomena are dependent on the species and its ability to adapt under stress conditions, such as low water activity caused by high levels of substrate concentration [8]. On the other hand, acetic acid is a toxic compound (in the non ionized form, under its $\mathrm{pKa}$ value) because that form could cross over the plasmatic membrane into the cell provoking a decrease in the intracellular $\mathrm{pH}$ value, a phenomenon that has been related to the denaturation of glycolytic enzymes and consequent reduction in the proton motive force causing the viability lost [5]. However, the resistance of Brettanomyces yeasts to acetic acid is similar to S. cerevisiae under aerobic conditions [8]. Consequently, the aim of this work was to evaluate the effect of glucose concentration on $B$. bruxellensis using the conditions previously reported by [2] with $\mathrm{pH}$ control to diminish the negative acid effect.

\section{Materials and Methods}

\subsection{Microorganism}

B. bruxellensis 6037 was obtained from the Institute of Hygiene and Epidemiology, Mycology Section (IHEM, Brussels, Belgium).

\subsection{Culture Media}

B. bruxellensis was preserved at $4^{\circ} \mathrm{C}$ using a basal medium with the following composition $\left(\mathrm{g} \cdot \mathrm{L}^{-1}\right)$ : glucose, 20 ; yeast extract, 20; and agar, 20. The preculture medium consisted of $\left(\mathrm{g} \cdot \mathrm{L}^{-1}\right)$ : glucose, 50; yeast extract, 1; $\mathrm{KH}_{2} \mathrm{PO}_{4}, 5.0:\left(\mathrm{NH}_{4}\right)_{2} \mathrm{SO}_{4}, 2.0$; and $\mathrm{MgSO}_{4} \cdot 7 \mathrm{H}_{2} \mathrm{O}, 0.4$. The initial $\mathrm{pH}$ was adjusted to 5.5 using $80 \%(\mathrm{v} / \mathrm{v})$ orthophosphoric acid solution. The preculture was made in $500 \mathrm{~mL}$ Erlenmeyer flasks containing $300 \mathrm{~mL}$ liquid medium previously sterilized in autoclave for $15 \mathrm{~min}$ at $121^{\circ} \mathrm{C}$. After inoculation, each Erlenmeyer flask was incubated at $30^{\circ} \mathrm{C}$ for $48 \mathrm{~h}$ and stirred at $250 \mathrm{rpm}$. A second preculture for $24 \mathrm{~h}$ was prepared to obtain inoculums containing $3 \times 10^{6}$ viable cells $\mathrm{m} \cdot \mathrm{L}^{-1}$.

\subsection{Culture Conditions}

Fermentations were carried out in a 2 L Bioflo 115 New Brunswick Scientific (Enfield, CT, USA) with a working volume of $1.5 \mathrm{~L}$ using the same medium than the preculture. The $\mathrm{pH}$ was controlled using $\mathrm{NaOH} 1 \mathrm{M}$. The agitation was fixed at $250 \mathrm{rpm}$. The oxygen transfer rate (OTR) was set in $121 \mathrm{mg} \mathrm{O} \mathrm{L}^{-1} \cdot \mathrm{h}^{-1}$ at $30^{\circ} \mathrm{C}$, according to Castro et al. [2] measured by the gassing-out method and using a Gauss-Newton function to diminishing the square sum error. Glucose concentrations were established from 1.2 to $220 \mathrm{~g} \cdot \mathrm{L}^{-1}$. The culture medium was sterilized in autoclave for $20 \mathrm{~min}$ at $121^{\circ} \mathrm{C}$.

\subsection{Analytical Techniques}

Yeast growth was measured by two techniques: 1) correlating optic density $(620 \mathrm{~nm})$ against cell weight dry and 2) direct count using a Thoma Chamber. Viability was obtained by using the methylene blue staining method [9]. In addition, the culture medium was centrifuged for 10 min at $10,000 \mathrm{rpm}$ and $4^{\circ} \mathrm{C}$ using an Eppendorf Centrifuge 5424 (Germany). The supernatant was stored at $-20^{\circ} \mathrm{C}$ until its analysis. Glucose, glycerol, acetic acid and ethanol were measured by high performance liquid chromatography (Waters 600, TSP Spectra System, Waters, Milford, MA, USA) using a Biorad Aminex HPX87H column (Bio-Rad Laboratories, Inc., Hercules, CA, USA). The temperature was $40^{\circ} \mathrm{C}$, mobile phase sulfuric acid $5 \mathrm{mM}$, flow rate $0.4 \mathrm{~mL} \cdot \mathrm{min}^{-1}$ and an index refraction detector (Waters 2414, TSP Refracto Monitor V, Waters) was used.

\section{Results and Discussion}

The influence of initial glucose concentration on acetic acid production by $B$. bruxellensis was evaluated in fermentation broths containing increasing amounts of glucose under aerobic conditions. Acetic acid and ethanol were the only metabolites detected, since glycerol was not found in this study, thus confirming the inability of this microorganism to produce this substance under aerobic conditions. Moulin et al. [4] attributed this behavior to the redox imbalance caused by oxygen presence. Figure 1 shows the course with time for glucose consumption, acetic acid and ethanol production, and increment of biomass.

Starting with only $1.2 \mathrm{~g} \cdot \mathrm{L}^{-1}$ initial glucose, nor ethanol or acetic acid was produced (Figure 1(a)) which can be explained due to the presence of Crabtree effect on this 
a)

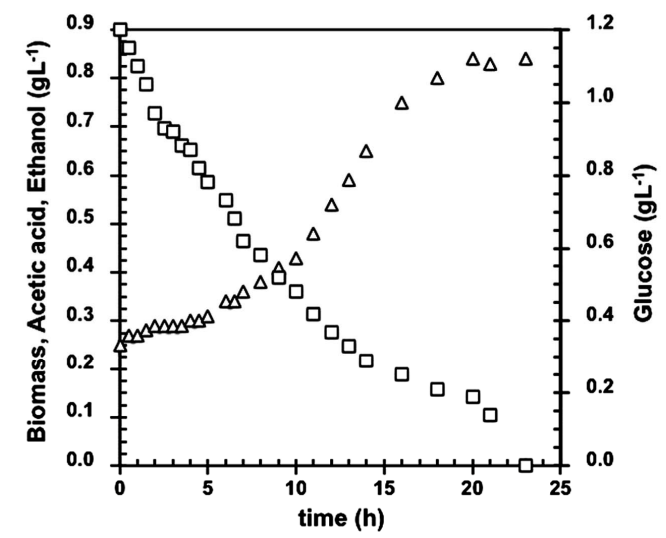

c)



e)
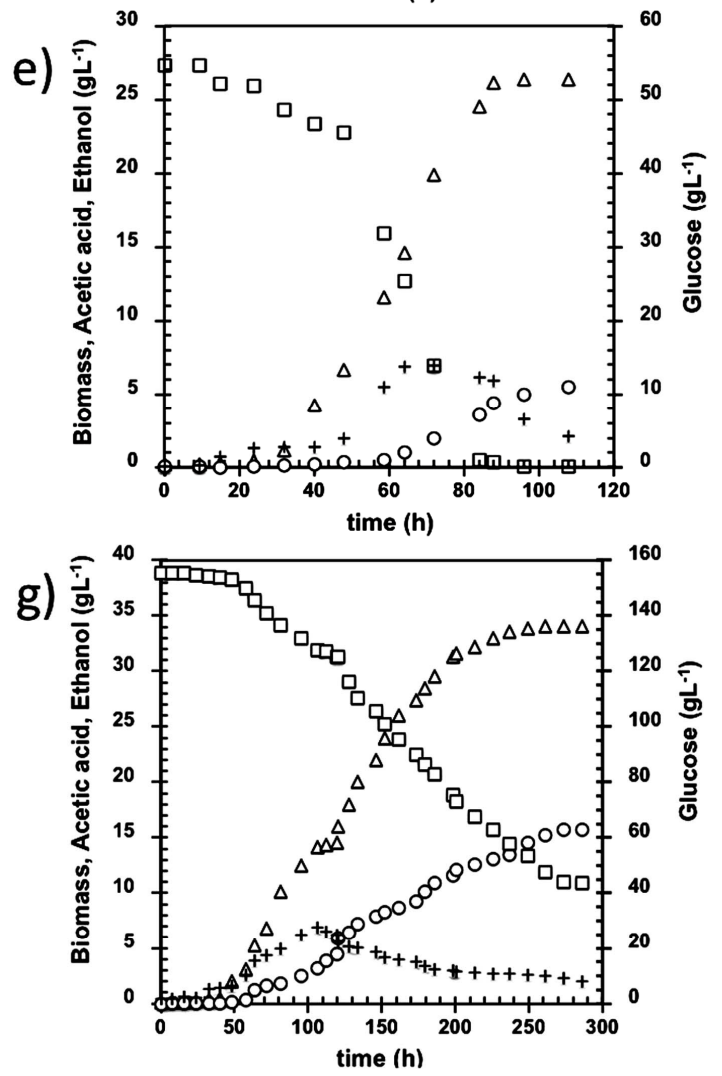

b)

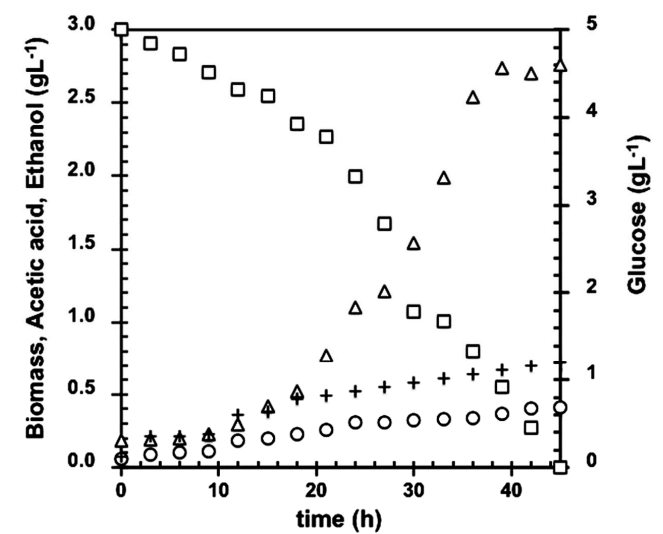

d)

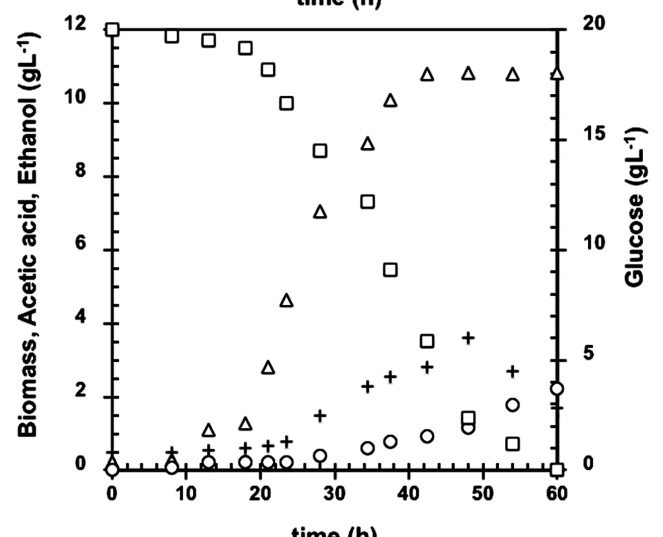

f)
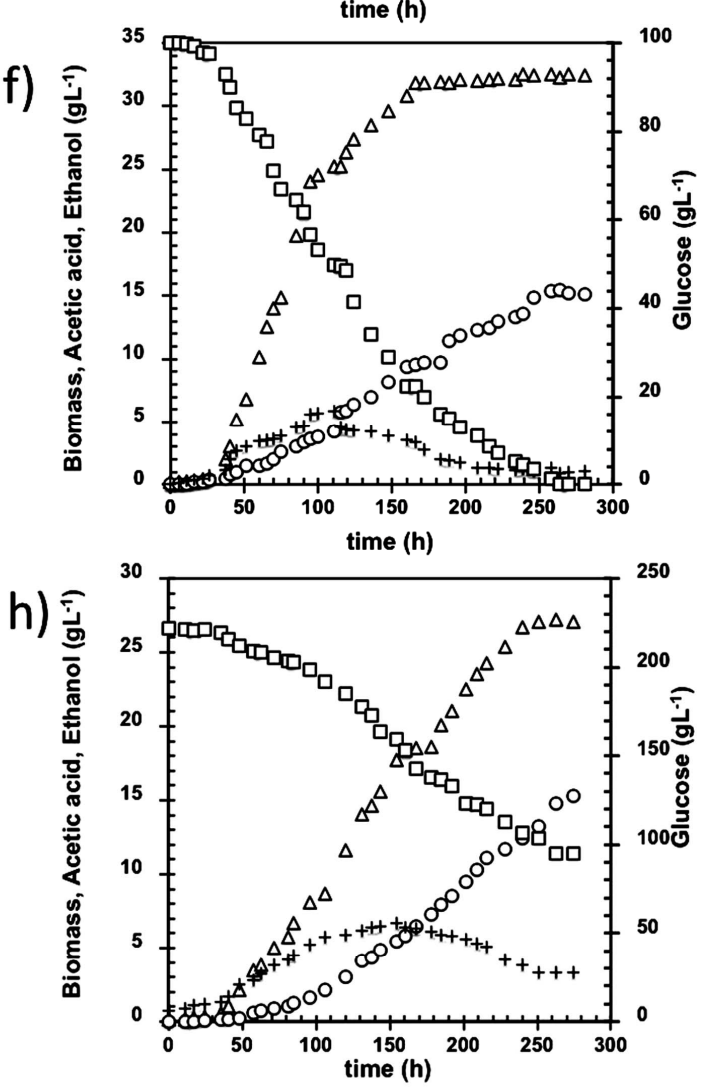

Figure 1. Kinetic of $B$. bruxellensis at different glucose initial concentration. Initial glucose concentration (g. $\left.\mathbf{L}^{-1}\right)$ : (a) 1.2; (b) 5 ; (c) 10; (d) 20; (e) 55; (f) 100; (g) 155 and (h) 220. Biomass (open triangles), Glucose (open square), Ethanol (cross), Acetic acid (open circle). 
yeast. Similarly, Walker [5] also observed this phenomenon on S. cerevisiae working with glucose concentrations in the vicinity of $0.9 \mathrm{~g} \cdot \mathrm{L}^{-1}$, hence, the Crabtree effect can be related to low glucose contents in the culture medium. This fact can be confirmed by the continuous reduction observed on biomass yield with the corresponding increment on initial glucose concentration (Figure 2), which is a characteristic kinetic behavior of the Crabtree effect on yeasts.

These results should be born in mind if the main goal is to increase the biomass production, for instance, by conducting a fed batch process. The kinetic behavior of $B$. bruxellensis at low glucose contents (Figure 3) demon-

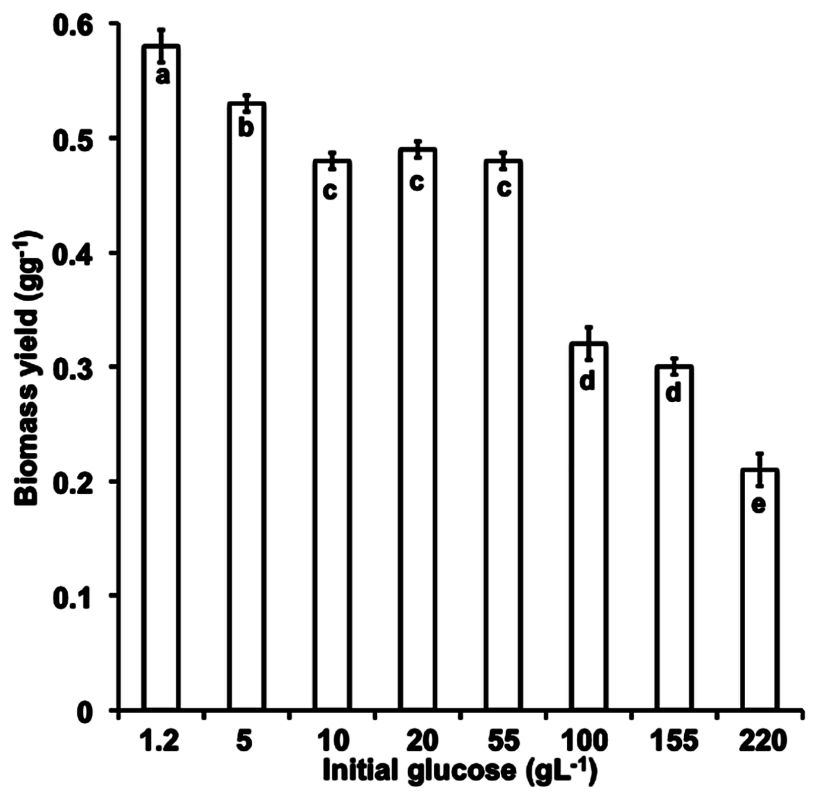

Figure 2. Biomass yield at different initial glucose concentration on B. bruxellensis. ANOVA P $=\mathbf{0 . 0 5}$.

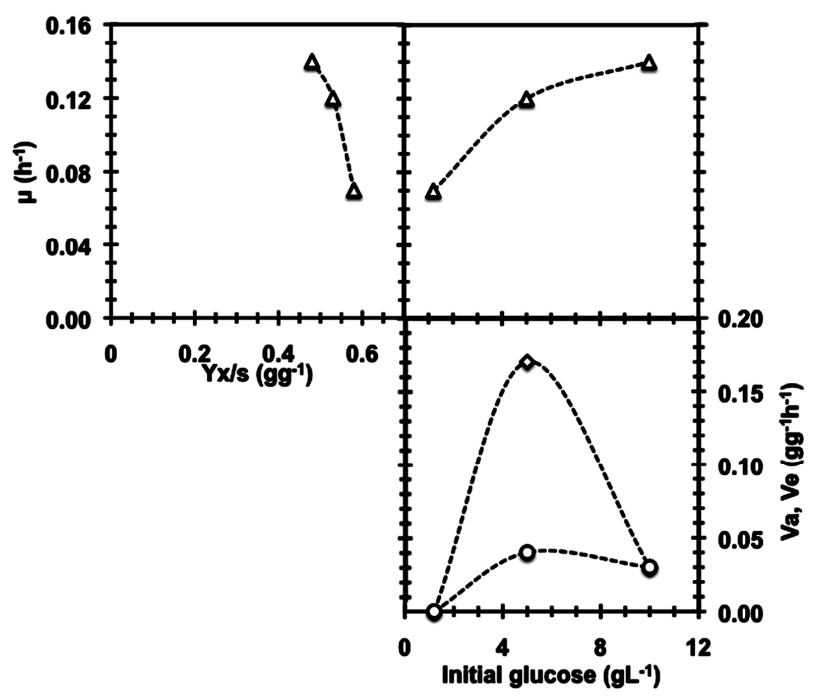

Figure 3. Kinetic behavior of Crabtree effect on $B$. bruxellensis. strates the occurrence of Crabtree effect on this yeast due to this is the typical profile established for Crabtree positive yeasts where the existence of a sugar content in which the main product specific production rate is zero, the biomass yield reaches a maximum value.

Using 5 and $10 \mathrm{~g} \cdot \mathrm{L}^{-1}$ initial glucose concentration (Figures 1(b) and (c)), B. bruxellensis metabolism has a second phase behavior in which ethanol started to be consumed to produce acetic acid after $36 \mathrm{~h}$ of fermentation, remaining glucose partially unconsumed. These results are not in accordance with those reported by Wijsman [6] who established that the second phase only begins when glucose on the culture media is completely depleted, although agree with the results achieved by Freer [1]. This variation could be due to because Wijsman [6] employed anaerobic and microaerobic conditions meanwhile Freer [1] and this work employed only aerobic conditions, thus emphasizing the role of dissolved oxygen into the regulation of the metabolic pathway on Brettanomyces yeasts. This behavior could be quite different to the observed with others yeasts, probably due to the occurrence of Custer and Crabtree effects on this specie.

Similar findings were perceived with $20 \mathrm{~g} \cdot \mathrm{L}^{-1}$ initial glucose (Figure 1(d)), because ethanol consumption could be associated to the low levels of residual glucose in the medium (around $2 \mathrm{~g} \cdot \mathrm{L}^{-1}$ in the last case). Conversely, increasing the initial glucose concentrations up to $50 \mathrm{~g} \cdot \mathrm{L}^{-1}$ the second growth phase was observed with residual concentrations of $14 \mathrm{~g} \cdot \mathrm{L}^{-1}$, which could be a consequence of synergistic effects of ethanol, acetic acid, and glucose concentrations in the culture media (Figure 1(e)).

Using $100 \mathrm{~g} \cdot \mathrm{L}^{-1}$ initial glucose concentrations, B. bruxellensis showed a diauxic growth (Figure 1(f)) previously reported by Brettanomyces yeasts under similar culture conditions [10]. This diauxic growth could be due to the acetic acid concentration reached the critic threshold of $4 \mathrm{~g} \cdot \mathrm{L}^{-1}$ after $100 \mathrm{~h}$ of fermentation Additionally, no glucose consumption was found at this time $(100-120 \mathrm{~h})$, which could be due to the hexokinase is the enzyme more seriously affected by acetic acid presence [11] thus avoiding the glucose catabolism. However, ethanol was consumed, indicating that the enzymes involved on the bioconversion from ethanol to acetic acid are not affected by acetic acid concentration at this level. After $120 \mathrm{~h}$, the glucose consumption continues because the yeast could express another hexokinase or because the synergistic effect of acetic acid, ethanol and glucose could be minor, that allowing glucose to be consumed.

The highest values of initial glucose considered in this study ranged between 150 and $220 \mathrm{~g} \cdot \mathrm{L}^{-1}$. In both cases, a prolonged lag phase of $24 \mathrm{~h}$ was observed during the growth of the yeast that could be related to substrate inhibition (Figures 1(g) and (h)), in fact, 44 and $90 \mathrm{~g} \cdot \mathrm{L}^{-1}$ 
of glucose, respectively remained unconsumed after 300 $\mathrm{h}$ fermentation. Nevertheless, this effect cannot be attributed to the lack of nutrients or vitamins, considering that the culture broth employed in this study were previously optimized by [12] to fulfill the nutrimental requirements of B. bruxellensis using high glucose concentrations. On the other hand, the acetic acid concentration achieved in these fermentation runs was $15.4 \mathrm{~g} \cdot \mathrm{L}^{-1}$, similar to the maximal concentration founded at $100 \mathrm{~g} \cdot \mathrm{L}^{-1}$ and overcoming the value of $13 \mathrm{~g} \cdot \mathrm{L}^{-1}$ reported [13]. The results point out that the maximum acetic acid concentration under the aerobic batch culture could be $15.4 \mathrm{~g} \cdot \mathrm{L}^{-1}$; suggesting that continuous or fed batch cultures must be carried out in order to diminish the acetic acid inhibition. This idea is supported by the strong reduction in the values of acetic acid yield collected in Figure 4, where it can be appreciated that the highest acetic acid yield $(0.16$ $\mathrm{g} \cdot \mathrm{g}^{-1}$ ) was achieved at $100 \mathrm{~g} \cdot \mathrm{L}^{-1}$ initial glucose.

Finally, considering that increasing concentrations of acetic acid directly influence the loss of cell viability, the following equation was calculated fitting the data according to Figure 5:

$$
\text { Viability }(\%)=100-1.27\left[\text { Acetic acid }\left(g \cdot \mathrm{L}^{-1}\right)\right]
$$

The correlation index $\left(\mathrm{R}^{2}\right)$ was 0.89 . This equation could be useful in order to determinate the maximum acetic acid concentration that $B$. bruxellensis can support during aerobic cultures under different operational conditions.

\section{Conclusion}

B. bruxellensis shows a Crabtree positive effect. Under

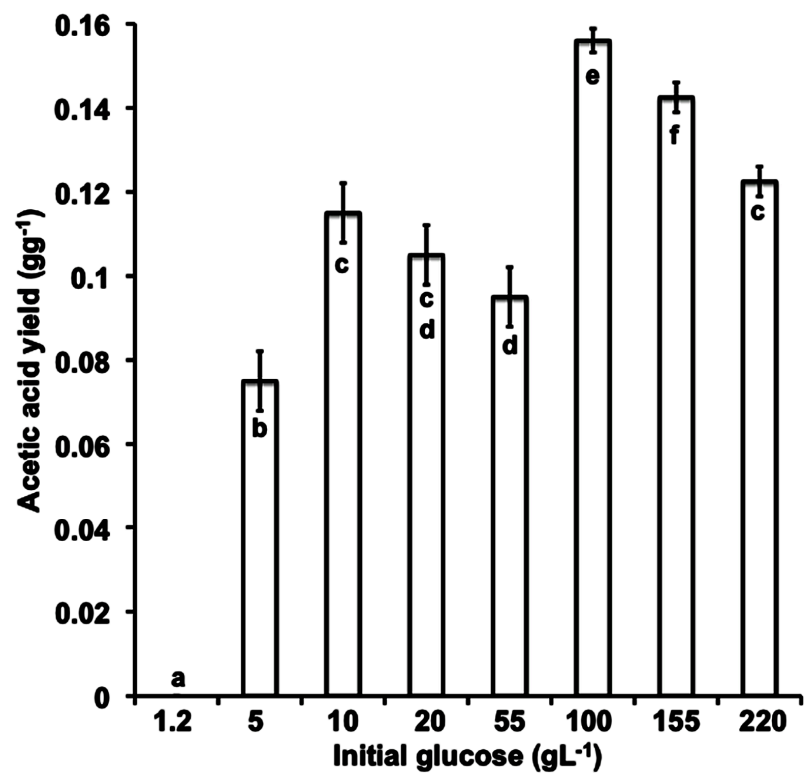

Figure 4. Acetic acid yield at different initial glucose concentration on $B$. bruxellensis. ANOVA $P=0.05$.

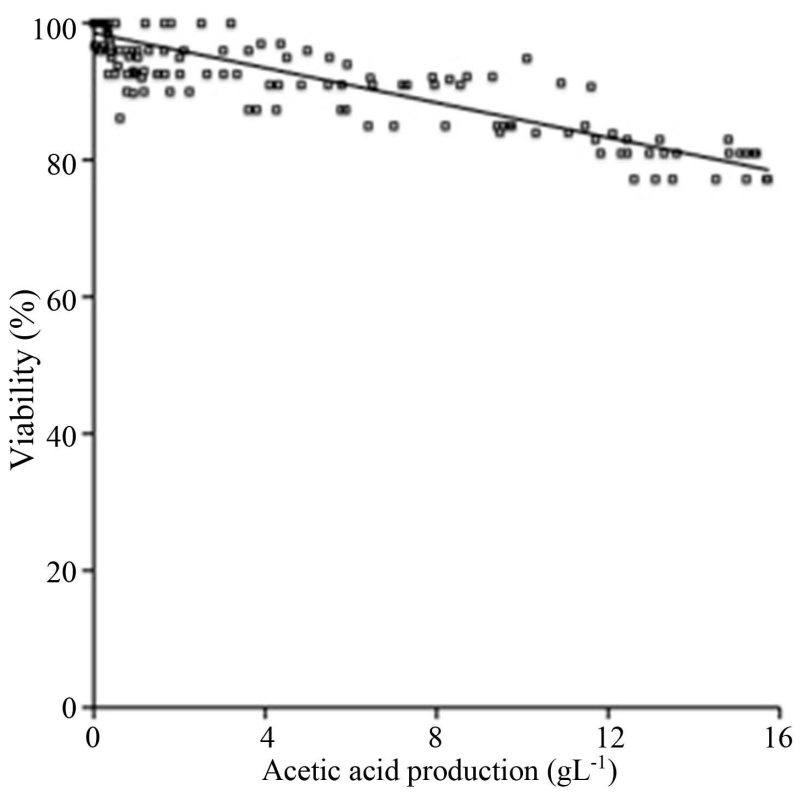

Figure 5. Relationship between acetic acid production and B. bruxellensis viability.

aerobic conditions glycerol production was not possible due to the redox imbalance for acid production; this imbalance can be controlled by oxygen supply. This phenomenon could help in order to understand the occurrence of Custer effect on yeasts. The incidence of second culture phase of $B$. bruxellensis improves acetic acid production because glucose and ethanol are consumed simultaneously. The initial glucose concentration affects seriously the acetic acid yield and its productivity. Initial glucose over $150 \mathrm{~g} \cdot \mathrm{L}^{-1}$ causes an inhibition that could be related to the glucose negative effect because neither acetic acid effect nor the lack of some nutrient was observed. The cell viability is a lineal function of acetic acid production. The best conditions for acetic acid production were obtained using $100 \mathrm{~g} \cdot \mathrm{L}^{-1}$ initial glucose concentration with an acetic acid yield of $0.154 \mathrm{~g} \cdot \mathrm{g}^{-1}$ and specific acetic acid production rates of $0.05 \mathrm{~g} \cdot \mathrm{g}^{-1} \cdot \mathrm{h}^{-1}$ with $77 \%$ of cell viability.

\section{Acknowledgements}

Authors acknowledged the economical support from the National Council of Science and Technology, México (Fondo Mixto CONACYT-Gobierno del Estado de Veracruz project No.128052) and the critical reading of Patricia Hayward Jones MSc. and Dulce Ma. Barradas Dermitz MSc.

\section{REFERENCES}

[1] S. Freer, "Acetic Acid Production by Dekkera/Brettanomyces Yeast," Journal Microbiology \& Biotechnology, Vol. 18, No. 3, 2002, pp. 271-275. doi:10.1023/A:1014927129259 
[2] C. Castro, B. I. Escudero, J. Gómez-Rodríguez, P. M Hayward-Jones and M. G. Aguilar-Uscanga, "Effect of Physical Factors on Acetic Acid Production in Brettanomyces Strain," Journal of Food Process Engineering, Vol. 28, No. 2, 2005, pp. 133-143. doi:10.1111/j.1745-4530.2005.00393.x

[3] W. A. Scheffers and T. O.Wiken, "The Custer Effect (Negative Pasteur Effect) as a Diagnostic Criterion for the Genus Brettanomyces," Antonie Van Leeuwenhock, Vol. 35, 1969, pp. 31-32.

[4] G. Moulin, H. Boze and P. Galzy, "Inhibition of Alcoholic Fermentation," Biotechnology Genetic Engineering Reviewer, Vol. 2, No. 1, 1984, pp. 365-382. doi:10.1080/02648725.1984.10647805

[5] G. M. Walker, "Yeast Physiology and Biotechnology," John Wiley \& Sons, Chichester, 1998.

[6] M. R. Wijsman, J. P. Van Dijken, B. H. A. Van Kleeff and W. A. Scheffers, "Inhibition of Fermentation and Growth in Batch Cultures of the Yeast Brettanomyces intermedius upon a Shift Aerobic to Anaerobic Conditions (Custer Effect)," Antonie van Leeuwenhoek, Vol. 50, No. 2, 1984, pp. 183-192. doi:10.1007/BF00400180

[7] M. G. Aguilar, M. L. Delia and P. Strehaiano, "Estudio Cinético Sobre el Crecimiento de B. bruxellensis en Glucosa Sobre Diferentes Concentraciones Iniciales de Ácido Acético," Microbiologie Aliments Nutrition, Vol. 17, 1999, pp. 181-190.

[8] B. Ortiz-Muñiz, O. Carvajal-Zarrabal, B. TorrestianaSánchez and M. G. Aguilar-Uscanga, "Kinetic Study on
Ethanol Production Using Saccharomyces cerevisiae ITV01 Yeast Isolated from Sugar Cane Molasses," Journal of Chemical Technology \& Biotechnology, Vol. 85, No. 10, 2010, pp. 1361-1367. doi:10.1002/jctb.2441

[9] H. Lange, J. M. Bovouzet, P. Taillander and C. Delorme, "Systematic Error and Comparison of Four Methods for Assessing the Viability of Saccharomyces cerevisiae Suspensions," Biotechnology Techniques, Vol. 7, No. 3, 1993, pp. 223-228. doi:10.1007/BF02566152

[10] S. Freer, B. Dien and S. Matsuda, "Production of Acetic Acid by Dekkera/Brettanomyces Yeast," World Journal of Microbiology and Biotechnology, Vol. 19, No. 1, 2003, pp. 101-105. doi:10.1023/A:1022592810405

[11] E. Pampulha and M. C. Loureiro, "Activity of Glycolytic Enzymes of Saccharomyces cerevisiae on the Presence of Acetic Acid," Applied Microbiology and Biotechnology, Vol. 34, No. 3, 1990, pp. 375-380. doi:10.1007/BF00170063

[12] M. G. Aguilar, M. L. Delia and P. Strehaiano, "Nutrimental Requirements of Brettanomyces bruxellensis: Growth and Physiology in Batch and Chemostat Cultures," Canadian Journal of Microbiology, Vol. 46, No. 11, 2000, pp. 1046-1050. doi:10.1139/cjm-46-11-1046

[13] M. Ciani and L. Ferraro, "Role of Oxygen on Acetic Acid Production by Brettanomyces/Dekkera in Winemarking", Journal of the Science of Food and Agriculture, Vol. 75, No. 4, 1997, pp. 489-495. doi:10.1002/(SICI)1097-0010(199712)75:4<489::AID-JS $\underline{\text { FA902 }>3.3 . \mathrm{CO} ; 2-0}$ 